\title{
Factors Affecting Adherence in a Pragmatic Trial of Annual Fecal Immunochemical Testing for Colorectal Cancer
}

\author{
Carrie M. Nielson, $P h D^{7}$, William M. Vollmer, $P h D^{7}$, Amanda F. Petrik, $M S^{7}$, Erin M. Keast, $M S^{7}$, \\ Beverly B. Green, $M D^{2}$, and Gloria D. Coronado, $P h D^{7}$
}

${ }^{1}$ Kaiser Permanente Center for Health Research, Portland, OR, USA; ${ }^{2}$ Kaiser Permanente Washington Health Research Institute, Seattle, WA, USA.

\begin{abstract}
BACKGROUND: Colorectal cancer screening by fecal immunochemical test (FIT) reduces the burden of colorectal cancer. However, effectiveness relies on annual adherence, which presents challenges for clinic staff and patients.
\end{abstract}

OBJECTIVE: Describe FIT return rates and identify factors associated with FIT adherence over 2 years in a mailed FIT outreach program in federally qualified health centers.

DESIGN: Observational study nested in the Strategies and Opportunities to Stop Colon Cancer in Priority Populations (STOP CRC) trial. Five thousand one hundred ninety-five patients had an initial FIT order and were followed for $\geq 2$ years (3574 also had a FIT order in the second year).

MAIN MEASURES: FIT return percent in each year and patient- and neighborhood-level characteristics associated with FIT adherence.

KEY RESULTS: Overall, the proportion of FIT orders that were completed was $46 \%$ in the patients' first year and $41 \%$ in the patients' second year. Of the 5195 patients with a FIT order in year 1, 3574 (69\%) also had a FIT order in year $2(71 \%$ of year 1 adherers and $67 \%$ of year 1 nonadherers, $p=0.009$ ). Among those with a FIT order in the second year, the FIT return rate was about twice as high among those who were adherent in the first year (952/ 1674 , or $57 \%$ ) as among those who were not (531/1900, or $28 \%, p<0.0001)$. Patient-level characteristics associated with higher odds of FIT return were a history of FIT screening at baseline, age over 65 (vs 50-65), no current tobacco use, recent receipt of a mammogram or flu vaccine, Asian ancestry (compared to non-Hispanic white), and non-English preference. The only neighborhood factor associated with lower FIT return rate was patient's larger residential city size.

CONCLUSION: Our findings can inform the customization of programs to promote FIT return among patients who receive care at federally qualified health centers.

TRIAL REGISTRATION: http: / /www.clinicaltrials.gov

KEY WORDS: colorectal; cancer; fecal immunochemical test; screening.

Electronic supplementary material The online version of this article (https://doi.org/10.1007/s11606-018-4820-0) contains supplementary material, which is available to authorized users.

Received May 16, 2018

Revised September 27, 2018

Accepted November 27, 2018

Published online January 25, 2019
J Gen Intern Med 34(6):978-85

DOI: $10.1007 / \mathrm{s} 11606-018-4820-0$

(C) Society of General Internal Medicine 2019

\section{INTRODUCTION}

Colorectal cancer is one of the most common causes of cancer morbidity and mortality in the USA. However, in the past three decades, its incidence has declined and survival has increased, concordant with increases in screening rates. ${ }^{1,2}$ This trend belies disparities in screening and treatment that cause higher mortality rates among those with the lowest socioeconomic status. ${ }^{3,4}$ Screening participation remains suboptimal in the USA, with $62 \%$ of age-eligible adults up to date. ${ }^{5}$ Rates are particularly low for low-income $(47 \%)$, uninsured $(25 \%)$, or minority racial/ethnic people $(47-59 \%){ }^{5}$

Initiating fecal immunochemical test (FIT) screening has been the focus of provider-, clinical-, and patient-based intervention studies. ${ }^{6-9}$ Patient reminders can improve screening rates by $5-15$ percentage points ${ }^{10}$; more intensive interventions, such as one-on-one interactions with patients and elimination of structural barriers, can improve rates by up to 42 percentage points. ${ }^{10}$ While initial screening increases the probability of screening in subsequent years, ${ }^{11}, 12$ annual rates of adherence are usually lower than those of initial screening. ${ }^{13}$,

${ }^{14}$ Repeat screening among FIT-negative patients and followup colonoscopy among FIT-positive patients are essential for optimal reductions in incidence and mortality. ${ }^{15-17}$ Repeat FIT screening rates vary; for example, reports show $1-54 \%$ (depending on clinic site within diverse US organizations) of those initially screened became consistent screening participants (defined as testing within every 15 months over 3 years). ${ }^{18}$

Patients without insurance or usual preventive care are at higher risk of non-adherence; ${ }^{19-21}$ however, clinic-level interventions have had modest to high impact on multiyear adherence in both insured and non-insured settings. ${ }^{22-}$ ${ }^{25}$ Understanding screening patterns can therefore inform population-specific screening strategies and messaging. We evaluated 2-year FIT screening rates among patients at federally qualified health centers. We determined the associations of patient and neighborhood characteristics with FIT screening over 2 years. 


\section{METHODS}

The Strategies and Opportunities to Stop Colon Cancer in Priority Populations (STOP CRC) study is a 26-clinic pragmatic study of mailed FIT outreach in federally qualified health centers in Oregon and California, USA. STOP CRC was a clinic-randomized trial used to test the use of a directmail approach to colorectal cancer screening compared to usual care. ${ }^{26}$ An introductory letter, FIT kit packet that included wordless instructions, ${ }^{27}$ and reminder letter were developed for STOP CRC, as previously described. ${ }^{28}$ Roll-out in intervention clinics occurred during 2014 and 2015, and this report is an observational study conducted within the intervention arm. The Institutional Review Board (IRB) of Kaiser Permanente Northwest (KPNW) approved study activities, and clinics ceded human subjects review authority to the KPNW IRB. Primary outcomes of the STOP CRC trial have been reported; ${ }^{29} 2$-year adherence is a secondary outcome.

\section{Patient Eligibility}

Patients were included if they were 50-74 years old during the year following clinic randomization (to ensure age eligibility for $\geq 1$ year), attended a clinic visit in the previous year, and were due for colorectal cancer screening. We defined "due for screening" as having no evidence in the electronic health record (EHR) of (1) FIT in the previous year, (2) an order for FIT in the previous 6 months, (3) flexible sigmoidoscopy in the previous 4 years, (4) colonoscopy in the previous 9 years, or (5) an order for a sigmoidoscopy/colonoscopy in the previous year. Patients were excluded if they had EHR evidence of a history of colorectal cancer, inflammatory bowel disease (e.g., ulcerative colitis or Crohn's disease), total colectomy, or renal failure. ${ }^{29,30}$

Eight health centers and 26 clinics participated in the trial. This analysis included clinics that delivered the intervention for at least 2 years (10 of the original 13 intervention clinics met this criterion, online Supplemental Table 1). Within these clinics, we included patients who received an initial FIT order and who had $\geq 1$ clinic visit in each of the 2 years after the initial FIT order (Fig. 1, online Supplemental Table 2). Henceforth, we refer to years 1 and 2 as they relate to the patient's initial FIT order. Patients' year 1 FIT orders occurred between June 2014 and July 2016 and subsequent year 2 orders occurred between July 2015 and July 2017. We restricted the year 2 FIT return data to participants who had a FIT order during their second year.

\section{Study Variables}

We captured the FIT completion from the EHR and extracted patient-level predictors: age, sex, body mass index (BMI), race, Hispanic ethnicity, primary language preference, insurance status, income (percent of federal poverty level (FPL)), tobacco use, history of FIT completion prior to the study, flu vaccination in the prior year, Pap smear (for women $\leq 65$ ) in the prior 3 years, and mammogram (for women) within the prior 2 years. We refer to the last four items as "preventive care" variables. The history of several chronic conditions within the year preceding initial study eligibility was constructed, along with the Charlson comorbidity index, from ICD-9 and ICD-10 codes. ${ }^{31}$

Neighborhood-level variables were from census tract data, except for emergency department visits per 1000 enrollees, which was a county-level variable from the Centers for Medicare \& Medicaid Services. Tract-level variables included the Gini coefficient (as a measure of income inequality), median household income, percent of households with FPL $<100 \%$, percent unemployment, percent with a bachelor's degree or higher, population density, and residential city size.

\section{Analytic Approach}

We used mixed effects logistic regression models to assess factors associated with FIT completion in either year, accounting for clustering of patients within clinics and of year within patients. Potential predictors with an unadjusted $p$ value $<0.20$ were retained for inclusion in multivariable modeling.

To determine factors independently associated with FIT completion, we used a stepwise variable selection procedure with backward elimination, requiring $p \leq 0.05$ for retention in the final model. ${ }^{32}$ Because history of FIT screening is a known strong predictor of subsequent FIT completion, we constructed the primary multivariable model without baseline history of FIT use as a predictor. In a secondary model, we included baseline history of FIT screening to see how it altered the effect size of other variables.

In addition to reporting odds ratios (ORs) from the multivariable model, we used the logistic regression model results to estimate marginally standardized probabilities of completing a FIT for the various predictors in the model, as well as differences in these probabilities between levels of the predictor variables. The effect of clinic on FIT return was quantified by the median OR, calculated by $e^{0.95 * \sqrt{\text { variance }}} .33$ The median OR can be interpreted as the effect on FIT return of a patient switching from a low-return clinic to a high-return clinic. Analyses were conducted in Stata 15.1 (StataCorp, College Station, TX).

\section{RESULTS}

Most participants were ages 50-59 years old (63\%), overweight or obese $(71 \%)$, white $(77 \%)$, and non-Hispanic $(82 \%)$. Almost half were covered by Medicaid (46\%) and $21 \%$ were uninsured; $47 \%$ had income below the federal poverty level. Approximately $60 \%$ of participants were up to date on flu vaccination or mammogram; $33 \%$ had ever completed a FIT (Table 1). Half of participants lived in cities with $>50,000$ residents, and their neighborhoods were marked by high unemployment ( $87 \%$ were above the national average), 


\section{Clinics with $\geq 2$ years of STOP CRC} intervention activities

$$
\mathrm{N}=10
$$

\begin{tabular}{|c|c|}
\hline $\begin{array}{l}\text { (A) Patients assigned to clinics } \geq 2 \text { years prior to the } \\
\text { clinics' end of intervention activities } \\
\qquad N=18,835\end{array}$ & \\
\hline & $\begin{array}{l}\text { Excluded due to lack of FIT order } \\
\text { during window of consideration* } \\
\qquad N=9,347\end{array}$ \\
\hline $\begin{array}{l}\text { (B) Patients with FIT order during window of } \\
\text { consideration* } \\
\qquad N=9,488\end{array}$ & \\
\hline 14 & $\begin{array}{l}\text { Excluded due to assumed transfer of } \\
\qquad \begin{array}{l}\text { care } \\
N=4,108\end{array}\end{array}$ \\
\hline
\end{tabular}

(C) Patients with office visit at assigned clinic in each of the 2 years following initial FIT order

$\mathrm{N}=5,380$

Cohort for evaluation of FIT screening
compliance in each year
$\mathrm{N}=5,195$

(D) Exclusionary diagnosis or a colonoscopy or FS prior to FIT order date $\mathrm{N}=185$

Figure 1 Inclusion in the analytic sample of FIT screening adherence. *Window of FIT order consideration: after patient eligibility, after start of clinic intervention activities, and at least 2 years prior to end of clinic's intervention activities. FIT, fecal immunochemical test; FS, flexible sigmoidoscopy; STOP CRC, Strategies and Opportunities to Stop Colon Cancer in Priority Populations.

low education ( $70 \%$ were in tracts with $\leq 30 \%$ college graduate), and high inequality ( $57 \%$ were in tracts with the Gini index $>0.41$, online Supplemental Table 3).

Of the 5195 patients with a FIT order in year 1, $3574(69 \%)$ also had a FIT order in year 2 (71\% of year 1 adherers and $67 \%$ of year 1 non-adherers, $p=0.009)$. Among the 5195 patients with a FIT order in year 1, $46 \%$ returned a completed FIT kit; among the 3574 who had a year 2 FIT order, $1483(41 \%)$ returned a FIT (57\% of 1674 year 1 adherers and $28 \%$ of 1900 year 1 non-adherers, $p<0.0001)$. Several baseline patient characteristics were associated with higher odds of subsequent FIT adherence (Table 2): older age, Asian race, Hispanic ethnicity, non-English preference, and either never or formerly using tobacco. All preventive care variables were associated with subsequent FIT completion, with prior FIT use and having a mammogram in the past 2 years being most strongly associated (Table 2). Diabetes was associated with slightly higher odds of screening, and depression and chronic 
Table 1 Baseline Patient Characteristics and Medical History $(N=$ 5195)

\begin{tabular}{|c|c|c|}
\hline & Number & Percent \\
\hline \multicolumn{3}{|l|}{ Age (years) } \\
\hline $50-59$ & 3005 & 63 \\
\hline $60-64$ & 1166 & 21 \\
\hline$\geq 65$ & 1024 & 16 \\
\hline Female & 2901 & 56 \\
\hline \multicolumn{3}{|l|}{ BMI $\left(\mathrm{kg} / \mathrm{m}^{2}\right)$} \\
\hline$<18.5$ & 64 & 1 \\
\hline $18.5-24.9$ & 1090 & 21 \\
\hline $25.0-29.9$ & 1452 & 28 \\
\hline$\geq 30$ & 2243 & 43 \\
\hline Ūnknown & 346 & 7 \\
\hline \multicolumn{3}{|l|}{ Race } \\
\hline White & 3987 & 77 \\
\hline Asian & 473 & 9 \\
\hline Black & 358 & 7 \\
\hline Other/unknown & 377 & 7 \\
\hline \multicolumn{3}{|l|}{ Ethnicity } \\
\hline Non-Hispanic & 4243 & 82 \\
\hline Hispanic & 765 & 15 \\
\hline Unknown & 187 & 4 \\
\hline \multicolumn{3}{|l|}{ Primary language } \\
\hline English & 3816 & 73 \\
\hline Spanish & 550 & 11 \\
\hline Other & 782 & 15 \\
\hline \multicolumn{3}{|l|}{ Insurance status } \\
\hline Medicaid & 2364 & 46 \\
\hline Medicare & 1237 & 24 \\
\hline Commercial & 468 & 9 \\
\hline Uninsured & 1078 & 21 \\
\hline Other/unknown & 48 & 1 \\
\hline \multicolumn{3}{|l|}{ Federal poverty level } \\
\hline$<100 \%$ & 2421 & 47 \\
\hline $100-150 \%$ & 969 & 19 \\
\hline $151-200 \%$ & 322 & 6 \\
\hline$>200 \%$ & 524 & 10 \\
\hline Unknown & 959 & 18 \\
\hline \multicolumn{3}{|l|}{ Tobacco use } \\
\hline Current & 1383 & 27 \\
\hline Never & 2170 & 42 \\
\hline Former & 1134 & 22 \\
\hline Unknown & 508 & 10 \\
\hline \multicolumn{3}{|l|}{ Comorbidities } \\
\hline Diabetes & 1457 & 28 \\
\hline Depression & 1235 & 24 \\
\hline Chronic pulmonary disease & 1093 & 21 \\
\hline \multicolumn{3}{|l|}{ Charlson index } \\
\hline 0 & 2484 & 48 \\
\hline 1 & 1664 & 32 \\
\hline 2 & 645 & 12 \\
\hline$\geq 3$ & 402 & 8 \\
\hline \multicolumn{3}{|l|}{ Preventive care } \\
\hline FIT prior to study & 1692 & 33 \\
\hline Flu vaccine in the past year & 3279 & 63 \\
\hline Pap in the past 3 years* & 1023 & 45 \\
\hline Mammogram in the past 2 years* & 1843 & 64 \\
\hline
\end{tabular}

BMI, body mass index; FIT, fecal immunochemical test

$*$ Percentages are of women $<65$ years old $(n=2288)$ for Pap and of all women $(n=2901)$ for mammogram

Primary language was unknown for two patients

pulmonary disease were associated with lower odds of screening (Table 2). No neighborhood-level characteristics were significantly associated with FIT completion (online Supplemental Table 3), although larger residential city size was associated with lower odds of FIT return with $p=0.05$ (e.g., OR for $>50,000$ inhabitants vs $<10,000$ inhabitants $=0.67$, Table 2), meeting the criterion for entering the multivariable model.
Table 2 Unadjusted Associations with FIT Completion over 2 Years in the STOP CRC Intervention Clinics

\begin{tabular}{|c|c|c|c|}
\hline & OR & $95 \% \mathrm{CI}$ & $p$ \\
\hline \multicolumn{3}{|l|}{ Year in study } & $<0.0001$ \\
\hline $1 \mathrm{st}$ & Ref & & \\
\hline 2 nd & 0.77 & $0.69-0.85$ & \\
\hline \multicolumn{3}{|l|}{ Age (years) } & 0.0001 \\
\hline$\leq 65$ & Ref & & \\
\hline$>65$ & 1.42 & $1.19-1.69$ & \\
\hline \multicolumn{3}{|l|}{ Sex } & 0.08 \\
\hline Male & Ref & & \\
\hline Female & 1.12 & $0.99-1.28$ & \\
\hline \multicolumn{3}{|l|}{ BMI $\left(\mathrm{kg} / \mathrm{m}^{2}\right)$} & 0.30 \\
\hline $\begin{array}{l}<18.5 \\
185-24.9\end{array}$ & $\begin{array}{l}0.80 \\
\text { Ref }\end{array}$ & $0.44-1.46$ & \\
\hline $\begin{array}{l}18.5-24.9 \\
25.0-29.9\end{array}$ & $\begin{array}{l}\text { Ref } \\
1.04\end{array}$ & $0.86-1.25$ & \\
\hline $\begin{array}{l}25.0-29.9 \\
\geq 30\end{array}$ & 0.90 & $0.76-1.08$ & \\
\hline \multicolumn{3}{|l|}{ Race } & $<0.0001$ \\
\hline White & Ref & & \\
\hline Asian & 3.04 & $2.37-3.90$ & \\
\hline Other & 0.91 & $0.70-1.17$ & \\
\hline \multicolumn{3}{|l|}{ Hispanic } & 0.004 \\
\hline No & Ref & & \\
\hline Yes & 1.32 & $1.09-1.60$ & \\
\hline \multicolumn{3}{|l|}{ Primary language } & $<0.0001$ \\
\hline English & Ref & & \\
\hline Spanish & 1.85 & $1.50-2.29$ & \\
\hline Other & 2.60 & $2.09-3.24$ & \\
\hline \multicolumn{3}{|l|}{ Tobacco use } & $<0.0001$ \\
\hline Current & Ref & & \\
\hline Never & 1.99 & $1.69-2.33$ & \\
\hline Former & 1.68 & $1.39-2.02$ & \\
\hline \multicolumn{4}{|l|}{ Comorbidities } \\
\hline Diabetes & 1.19 & $1.03-1.38$ & 0.02 \\
\hline Depression & 0.85 & $0.73-0.99$ & 0.04 \\
\hline Chronic pulmonary disease & 0.82 & $0.70-0.96$ & 0.02 \\
\hline \multicolumn{3}{|l|}{ Charlson index } & 0.71 \\
\hline $0-2$ & Ref & & \\
\hline$\geq 3$ & 0.96 & $0.75-1.22$ & \\
\hline \multicolumn{4}{|l|}{ Preventive care } \\
\hline \multicolumn{3}{|l|}{ FIT prior to study } & $<0.0001$ \\
\hline No & Ref & & \\
\hline Yes & 3.00 & $2.58-3.47$ & \\
\hline \multicolumn{3}{|l|}{ Flu vaccine in the past year } & $<0.0001$ \\
\hline No & Ref & & \\
\hline Yes & 1.35 & $1.17-1.55$ & \\
\hline \multicolumn{3}{|c|}{ Pap in the past 3 years (among women $\leq 65$ ) } & 0.001 \\
\hline No & Ref & & \\
\hline Yes & 1.38 & $1.14-1.67$ & \\
\hline \multicolumn{3}{|c|}{ Mammogram in past 2 years (among women) } & $<0.0001$ \\
\hline No & Ref & & \\
\hline Yes & 1.99 & $1.66-2.40$ & \\
\hline \multicolumn{3}{|l|}{ Residential city size (inhabitants) } & 0.05 \\
\hline$<10,000$ & Ref & & \\
\hline $10-50,000$ & 0.89 & $0.72-1.10$ & \\
\hline$>50,000$ & 0.67 & $0.49-0.93$ & \\
\hline
\end{tabular}

OR, odds ratio; CI, confidence interval; BMI, body mass index; FIT, fecal immunochemical test

All models account for clustering of patients within clinic and of year of follow-up within patient

Primary language was unknown for two patients

In the primary multivariable analysis, the odds of FIT completion in the second year were significantly lower than those in the first year: predicted probabilities of FIT return dropped from 44 to $38 \%$ (Table 3). Associations with FIT completion (in either year) were being over 65 (vs $\leq 65$ ), being Asian (vs white race), having a non-English preference (vs English), not using tobacco, having obtained a mammogram in the past 2 years or a flu vaccine in the past year, and living in a smaller city (Table 3 ). The median OR for clinic differences was 1.44 (95\% CI 1.21-1.98), indicating a patient's relative 
Table 3 Multivariable Adjusted Associations with FIT Completion over 2 Years in the STOP CRC Intervention Clinics, Excluding Baseline History of FIT Use

\begin{tabular}{|c|c|c|c|c|c|}
\hline & OR & $95 \% \mathrm{CI}$ & $p$ & $\begin{array}{l}\text { Predicted probability } \\
\text { of FIT return }(\%)\end{array}$ & $\begin{array}{l}\text { Difference in predicted } \\
\text { prob. of FIT return }(\%)\end{array}$ \\
\hline Year in study & & & $<0.0001$ & & \\
\hline $1 \mathrm{st}$ & Ref & & & 44 & \\
\hline 2nd & 0.77 & $0.69-0.87$ & & 38 & -6 \\
\hline Age (years) & & & 0.03 & & \\
\hline$\leq 65$ & Ref & & & 41 & \\
\hline$>65$ & 1.23 & $1.02-1.49$ & & 45 & 4 \\
\hline Race & & & $<0.0001$ & & \\
\hline White & Ref & & & 40 & \\
\hline Asian & 2.01 & $1.48-2.73$ & & 56 & 16 \\
\hline Other & 0.92 & $0.71-1.19$ & & 38 & -2 \\
\hline Primary language & & & 0.002 & & \\
\hline English & Ref & & & 39 & \\
\hline Spanish & 1.36 & $1.05-1.78$ & & 46 & 7 \\
\hline Other & 1.54 & $1.16-2.06$ & & 49 & 10 \\
\hline Tobacco use & & & $<0.0001$ & & \\
\hline Current & Ref & & & 34 & \\
\hline Never & 1.64 & $1.38-1.96$ & & 45 & 11 \\
\hline Former & 1.53 & $1.26-1.85$ & & 43 & 9 \\
\hline Flu vaccine in the past year & & & 0.008 & & \\
\hline No & Ref & & & 38 & \\
\hline Yes & 1.22 & $1.05-1.42$ & & 43 & 5 \\
\hline Mammogram in past 2 years (among women) & & & $<0.0001$ & & \\
\hline No & Ref & & & 37 & \\
\hline Yes & 1.80 & $1.47-2.19$ & & 50 & 13 \\
\hline Residential city size (inhabitants) & & & 0.02 & & \\
\hline$<10,000$ & Ref & & & 47 & \\
\hline $10-50,000$ & 0.93 & $0.75-1.15$ & & 46 & -1 \\
\hline$>50,000$ & 0.61 & $0.44-0.86$ & & 36 & -11 \\
\hline
\end{tabular}

OR, odds ratio; CI, confidence interval; BMI, body mass index; FIT, fecal immunochemical test

Model accounts for clustering of patients within clinic and of year of follow-up within patient, as well as all other variables in the table

Primary language was unknown for two patients

median odds of returning a FIT if s/he attends a clinic with a higher FIT return rate as compared to a clinic with a lower FIT return rate.

The largest absolute differences in predicted probability from the multivariable model of FIT completion were for race (the probability for Asian patients was $56 \%$, compared to $40 \%$ for white patients) and for mammogram use (50\% probability for women who had completed a mammogram in the past 2 years vs $37 \%$ for those who had not; Table 3). When baseline history of FIT use was included in the multivariable model, it was a strong predictor of FIT adherence $(\mathrm{OR}=2.68,95 \% \mathrm{CI}$ 2.29-3.14; data not shown). The adjusted probability of FIT completion among those with a baseline history of FIT use was $58 \%$ and was $35 \%$ among those who had never completed a FIT. Associations were similar, though somewhat weaker, for most variables when this variable was included in another multivariable analysis, except that age and flu vaccine variables were not retained in the final model (online Supplemental Table 4).

\section{DISCUSSION}

In this study of mailed FIT outreach in federally qualified health centers, patients who attended the intervention clinics and were offered FIT had completion rates of approximately $40 \%$ in both years. Odds of adherence were significantly greater for those who did not use tobacco and who had a history of preventive care receipt. Patients who had Asian ancestry and preferred non-English languages also had higher odds of FIT adherence.

Our observation of adherence over 2 years was similar to other longitudinal screening studies in the USA. In a trial of mailed FIT in Washington state primary care clinics, $37 \%$ of usual care patients and $53 \%$ in the intervention group received screening in the third year of follow-up. ${ }^{23}$ Intervention participant screening uptake was highest among participants who had completed fecal testing in both years 1 and 2, 77\% in year 3 , compared to $45 \%$ and $18 \%$ among participants completing one or none of the two prior mailed fecal tests, respectively. Our study supported these results, with approximately double the year 2 FIT return rate among year 1 FIT adherers $(58 \%)$ as non-adherers. In community health centers in Louisiana, second-year FIT completion was 33-59\%, and only nurse education and phone support improved rates (from 33-38\% to $59 \%$ ) but was costly ( $\$ 2450$ per person screened). ${ }^{34}$ A more intensive intervention (e.g., text reminders and multiple nurses' calls) achieved a repeat adherence rate of $82 \%$ in a Chicago health center. ${ }^{35}$ High rates of repeated screening (> $70 \%$ ) among those who adhere in the first year were also demonstrated in Italy ${ }^{36}$ and Norway ${ }^{37}$ and in the Kaiser Permanente system. ${ }^{38}$

We previously reported baseline factors associated with being up to date on screening in the STOP CRC health centers before the intervention began. Patients were more likely to be 
up to date on CRC screening if they were aged 65 or older, insured, had more previous outpatient visits, and were currently on other preventive screenings. ${ }^{39}$ In our previous study, the STOP CRC intervention had not yet been introduced, and the proportion of patients who were up to date for CRC screening by fecal testing was relatively low (18\%). Fecal testing rates rose from $7 \%$ in 2010 to $21 \%$ in 2015 . In our current analysis, although FIT completion continued to improve over 2015 rates, several of the same predictors of adherence remained. A US Preventive Services Task Force report in 2016 updated the 2008 CRC screening recommendations; however, annual FIT remained a consistent recommendation, and no changes in the STOP CRC intervention were implemented. ${ }^{40}$

Our study confirms the co-occurrence of CRC screening with other health behaviors. Recent mammogram and Pap screening, as well as cholesterol check, were strongly associated (ORs $\geq 3$ ) with fecal testing in the past year in the large, US population-based Behavioral Risk Factor Surveillance System results. ${ }^{41}$ In addition, current smokers, as well as those who were sedentary or reported $<2$ daily fruit and vegetable servings, were significantly less likely to have been up to date on fecal testing. ${ }^{41}$

In our analyses, self-identification as Asian was strongly associated with FIT completion. This observation might seem surprising, given that national Asian American colon cancer screening rates are lower than those of other racial groups. In 2015, 52\% of Asian Americans, 64\% of white, and 59\% of black Americans were up to date on colorectal cancer screening. ${ }^{5}$ However, access to care has been identified as a strong barrier in this group, ${ }^{42}$ and in a previous trial, we observed higher screening rates among Asian patients than among any other racial/ethnic group across all intervention arms. ${ }^{43}$ Likewise, our current study suggests high adherence in this patient subpopulation when access barriers are mitigated.

Interestingly, preference for a language other than English was associated with greater FIT completion in our study. NonEnglish preference was also associated with being up to date with FIT (vs colonoscopy) in the years prior to the STOP CRC intervention in this clinic population. ${ }^{39}$ More than 90 different languages were preferred by patients in these clinics, and the most common - other than English and Spanish - were Arabic, Chinese, Nepali, Russian, Somali, and Vietnamese. Confusing FIT kit instructions have been identified as a barrier to FIT adherence even among native English speakers, and we have reported on patient preference for wordless instructions over simplified English or Spanish instructions. ${ }^{27}$ Wordless instructions in STOP CRC may have provided an opportunity for patients who were predisposed to comply with screening but had language barriers to previous screening opportunities. Well-designed wordless instructions could lead to higher screening rates for many patients with written-language barriers and merit further investigation.

This study had several limitations. As a pragmatic trial, our study made use of unobtrusive collection of patient data through EHR review, an efficient method to ascertain outcomes but with some data challenges. ${ }^{44}$ For analyses of comorbidities, we used the diagnosis codes recorded during the year prior to screening eligibility and determined the Charlson index based on these codes. ${ }^{31}$ While our results showed no independent association between comorbidities and FIT completion, comorbidity ascertainment over a longer period or using a different index of comorbidity burden may yield different results. The Charlson index has been validated to predict mortality; other indices may be better predictors of health care utilization. ${ }^{45}$ We might have missed information on health reasons for non-participation in screening; for example, women without a cervix or with HPV co-testing during a Pap within the past 5 years would be misclassified as "nonadherent" for Pap screening. This subset who sought care is likely to be less healthy and may not be representative of the larger population of potential patients eligible for FIT screening. Similarly, because all clinics were within federally qualified health centers, we cannot assume results are generalizable to a broader patient population. Our study population was defined by health care encounters in the system, and health services outside this system may have introduced errors. Finally, our study was limited to 2 years.

Our study has implications for future research and practice. Much research has focused on how to improve FIT uptake among clinicians and patients. We recently reported the primary results of the STOP CRC trial, which demonstrated that clinic-level proportions of adults who completed a FIT were greater in the mailed FIT intervention group (13.9\%) than in control clinics (10.4\%). ${ }^{29}$ And we continue to investigate the best methods for reaching and reminding patients to return their FIT once it is mailed. ${ }^{28}$ These efforts are beneficial, because adherence to FIT screening is higher among those with a history of FIT completion. However, annual adherence in federally qualified health centers requires distinct research and implementation efforts and more research should identify the best methods for reaching patients in these settings. Strategies to promote CRC screening in patients with infrequent clinic visits may also be needed in this population.

Acknowledgments: Research reported in this publication was supported by the National Cancer Institute of the National Institutes of Health under Award Number UH3CA188640.

Corresponding Author: Gloria D. Coronado, PhD; Kaiser Permanente Center for Health Research, 3800 N. Interstate Ave., Portland, OR 97227, USA (e-mail: gloria.d.coronado@kpchr.org). Compliance with Ethical Standards:

Conflict of Interest: Dr. Coronado served as a co-investigator on a study funded by Epigenomics and as a principal investigator on a study funded by Quidel Corporation. The studies had no influence on the design, conduct, or reporting of the present study. All remaining authors declare that they do not have a conflict of interest.

Disclaimer: The content is solely the responsibility of the authors and does not necessarily represent the official views of the National Institutes of Health. The study sponsor had no role in study design; collection, analysis, and interpretation of data; writing the report; or the decision to submit the report for publication. 
Publisher's note: Springer Nature remains neutral with regard to jurisdictional claims in published maps and institutional affiliations.

\section{REFERENCES}

1. Murphy CC, Sandler RS, Sanoff HK, Yang YC, Lund JL, Baron JA Decrease in Incidence of Colorectal Cancer Among Individuals 50 Years or Older After Recommendations for Population-based Screening. Clin Gastroenterol Hepatol. 2017;15(6):903-9 e6. https://doi.org/10.1016/j. cgh.2016.08.037

2. Siegel RL, Miller KD, Fedewa SA, Ahnen DJ, Meester RGS, Barzi A, et al. Colorectal cancer statistics, 2017. CA Cancer J Clin. 2017;67(3):177-93. https://doi.org/10.3322/caac.21395

3. Teng AM, Atkinson J, Disney G, Wilson N, Blakely T. Changing socioeconomic inequalities in cancer incidence and mortality: Cohort study with 54 million person-years follow-up 1981-2011. Int J Cancer. 2017;140(6):1306-16. https://doi.org/10.1002/ijc.30555

4. Breen N, Lewis DR, Gibson JT, Yu M, Harper S. Assessing disparities in colorectal cancer mortality by socioeconomic status using new tools: health disparities calculator and socioeconomic quintiles. Cancer Causes Control. 2017;28(2):117-25. https://doi.org/10.1007/s10552-016-0842-2

5. White A, Thompson TD, White MC, Sabatino SA, de Moor J, DoriaRose PV, et al. Cancer Screening Test Use - United States, 2015. MMWR Morb Mortal Wkly Rep. 2017;66(8):201-6. https://doi.org/10.15585/ mmwr.mm6608al

6. Gupta S, Halm EA, Rockey DC, Hammons M, Koch M, Carter E, et al. Comparative effectiveness of fecal immunochemical test outreach, colonoscopy outreach, and usual care for boosting colorectal cancer screening among the underserved: a randomized clinical trial. JAMA Intern Med. 2013;173(18):1725-32. https://doi.org/10.1001/jamainternmed. 2013.9294

7. Daly JM, Levy BT, Moss CA, Bay CP. System Strategies for Colorectal Cancer Screening at Federally Qualified Health Centers. Am J Public Health. 2015;105(1):212-9. https://doi.org/10.2105/AJPH.2013. 301790

8. Davis SN, Christy SM, Chavarria EA, Abdulla R, Sutton SK, Schmidt AR, et al. A randomized controlled trial of a multicomponent, targeted, low-literacy educational intervention compared with a nontargeted intervention to boost colorectal cancer screening with fecal immunochemical testing in community clinics. Cancer. 2017;123(8):1390-400. https://doi.org/10.1002/cncr.30481

9. Myers RE, Sifri R, Hyslop T, Rosenthal M, Vernon SW, Cocroft J, et al. A randomized controlled trial of the impact of targeted and tailored interventions on colorectal cancer screening. Cancer. 2007;110(9):208391. https://doi.org/10.1002/cncr.23022

10. Holden DJ, Jonas DE, Porterfield DS, Reuland D, Harris R. Systematic review: enhancing the use and quality of colorectal cancer screening. Ann Intern Med. 2010;152(10):668-76. https://doi.org/10.7326/0003-4819152-10-201005180-00239

11. Fenton JJ, Elmore JG, Buist DS, Reid RJ, Tancredi DJ, Baldwin LM Longitudinal adherence with fecal occult blood test screening in community practice. Ann Fam Med. 2010;8(5):397-401. https://doi.org/10. 1370/afm. 1133

12. Myers RE, Balshem AM, Wolf TA, Ross EA, Millner L. Adherence to continuous screening for colorectal neoplasia. Med Care. 1993;31(6):50819.

13. Denters MJ, Deutekom M, Bossuyt PM, van Rijn AF, Fockens $\mathbf{P}$, Dekker E. Involvement of previous non-participants cannot fully compensate for lower participation in a second round of FIT-screening. Cancer Epidemiol. 2013;37(3):330-5. https://doi.org/10.1016/j.canep. 2013.01.007

14. Gellad ZF, Stechuchak KM, Fisher DA, Olsen MK, McDuffie JR, Ostbye T, et al. Longitudinal adherence to fecal occult blood testing impacts colorectal cancer screening quality. Am $\mathrm{J}$ Gastroenterol. 2011;106(6):1125-34. https://doi.org/10.1038/ajg.2011.11

15. Winawer SJ, Fischer SE, Levin B. Evidence-Based, Reality-Driven Colorectal Cancer Screening Guidelines: The Critical Relationship of Adherence to Effectiveness. JAMA. 2016;315(19):2065-6. https://doi. org/10.1001/jama.2016.3377

16. Jorgensen OD, Kronborg $\mathbf{O}$, Fenger $\mathrm{C}$. A randomised study of screening for colorectal cancer using faecal occult blood testing: results after 13 years and seven biennial screening rounds. Gut. 2002;50(1):29-32.
17. Shaukat A, Mongin SJ, Geisser MS, Lederle FA, Bond JH, Mandel JS, et al. Long-term mortality after screening for colorectal cancer. N Engl $J$ Med. 2013;369(12):1106-14. https://doi.org/10.1056/NEJMoa1300720

18. Singal AG, Corley DA, Kamineni A, Garcia M, Zheng Y, Doria-Rose PV, et al. Patterns and predictors or repeat fecal immunochemical and occult blood test screening in four large health care systems in the United States. Am J Gastroenterol. 2018. https://doi.org/10.1038/s41395018-0023-x

19. Zhao G, Okoro CA, Li J, Town M. Health Insurance Status and Clinical Cancer Screenings Among U.S. Adults. Am J Prev Med. 2018;54(1):e1 1e9. https://doi.org/10.1016/j.amepre.2017.08.024

20. DeVoe JE, Fryer GE, Phillips R, Green L. Receipt of preventive care among adults: insurance status and usual source of care. Am J Public Health. 2003;93(5):786-91.

21. Fenton JJ, Franks P, Reid RJ, Elmore JG, Baldwin LM. Continuity of care and cancer screening among health plan enrollees. Med Care. 2008;46(1):58-62. https://doi.org/10.1097/MLR.0b013e318148493a

22. Baker DW, Brown T, Goldman SN, Liss DT, Kollar S, Balsley K, et al. Two-year follow-up of the effectiveness of a multifaceted intervention to improve adherence to annual colorectal cancer screening in community health centers. Cancer Causes Control. 2015;26(11):1685-90. https:// doi.org/10.1007/s10552-015-0650-0

23. Green BB, Anderson ML, Chubak J, Fuller S, Meenan RT, Vernon SW. Impact of continued mailed fecal tests in the patient-centered medical home: Year 3 of the Systems of Support to Increase Colon Cancer Screening and Follow-Up randomized trial. Cancer. 2016;122(2):312-21. https://doi.org/10.1002/cncr.29734

24. Janda M, Hughes KL, Auster JF, Leggett BA, Newman BM. Repeat participation in colorectal cancer screening utilizing fecal occult blood testing: a community-based project in a rural setting. $\mathrm{J}$ Gastroenterol Hepatol. 2010;25(10):1661-7. https://doi.org/10.1111/j.1440-1746. 2010.06405.x

25. Murphy CC, Vernon Sw, Haddock NM, Anderson ML, Chubak J, Green BB. Longitudinal predictors of colorectal cancer screening among participants in a randomized controlled trial. Prev Med. 2014;66:12330. https://doi.org/10.1016/j.ypmed.2014.06.013

26. Coronado GD, Vollmer WM, Petrik A, Taplin SH, Burdick TE, Meenan RT, et al. Strategies and Opportunities to STOP Colon Cancer in Priority Populations: design of a cluster-randomized pragmatic trial. Contemp Clin Trials. 2014;38(2):344-9. https://doi.org/10.1016/j.cct.2014.06. 006

27. Coronado GD, Sanchez J, Petrik A, Kapka T, DeVoe J, Green B. Advantages of wordless instructions on how to complete a fecal immunochemical test: lessons from patient advisory council members of a federally qualified health center. J Cancer Educ. 2014;29(1):86-90. https://doi.org/10.1007/s13187-013-0551-4

28. Coronado GD, Rivelli JS, Fuoco MJ, Vollmer WM, Petrik AF, Keast E, et al. Effect of Reminding Patients to Complete Fecal Immunochemical Testing: A Comparative Effectiveness Study of Automated and Live Approaches. J Gen Intern Med. 2018;33(1):72-8. https://doi.org/10. 1007/s11606-017-4184-x

29. Coronado GD, Petrik AF, Keast EM, Vollmer WM, Taplin SH, Fields S, et al. Effectiveness of a Pragmatic Direct-Mail Colorectal Cancer Screening Program in Safety Net Clinics. JAMA Int Med. 2018.

30. Petrik AF, Green BB, Vollmer WM, Le T, Bachman B, Keast E, et al. The validation of electronic health records in accurately identifying patients eligible for colorectal cancer screening in safety net clinics. Fam Pract. 2016;33(6):639-43. https://doi.org/10.1093/fampra/cmw065

31. Guan H, Sundararajan V, Halfon P, Fong A, Burnand B, Luthi JC, et al. Coding algorithms for defining comorbidities in ICD-9-CM and ICD-10 administrative data. Med Care. 2005;43(11):1130-9.

32. Darlington RB, Hayes AF. Regression for Prediction. Regression Analysis and Linear Models: Concepts, Applications, and Implementation 1st ed. New York: Guilford Press; 2016.

33. Merlo J, Chaix B, Ohlsson H, Beckman A, Johnell K, Hjerpe P, et al. A brief conceptual tutorial of multilevel analysis in social epidemiology: using measures of clustering in multilevel logistic regression to investigate contextual phenomena. J Epidemiol Community Health. 2006;60(4):290-7. https://doi.org/10.1136/jech.2004.029454

34. Davis TC, Arnold CL, Bennett CL, Wolf MS, Reynolds C, Liu D, et al. Strategies to improve repeat fecal occult blood testing cancer screening. Cancer Epidemiol Biomarkers Prev. 2014;23(1):134-43. https://doi.org/ 10.1158/1055-9965.EPI-13-0795

35. Baker DW, Brown T, Buchanan DR, Weil J, Balsley K, Ranalli L, et al. Comparative effectiveness of a multifaceted intervention to improve adherence to annual colorectal cancer screening in community health 
centers: a randomized clinical trial. JAMA Intern Med. 2014;174(8):123541. https://doi.org/10.1001/jamainternmed.2014.2352

36. Zorzi M, Hassan C, Capodaglio G, Fedato C, Montaguti A, Turrin A et al. Long-term performance of colorectal cancer screening programmes based on the faecal immunochemical test. Gut. 2017. https://doi.org/ 10.1136/gutjnl-2017-314753

37. Knudsen MD, Berstad P, Hjartaker A, Gulichsen EH, Hoff G, de Lange $\mathbf{T}$, et al. Lifestyle predictors for non-participation and outcome in the second round of faecal immunochemical test in colorectal cancer screening. Br J Cancer. 2017. https://doi.org/10.1038/bjc.2017.189

38. Jensen CD, Corley DA, Guinn VP, Doubeni CA, Zauber AG, Lee JK, et al. Fecal Immunochemical Test Program Performance Over 4 Rounds of Annual Screening: A Retrospective Cohort Study. Ann Intern Med. 2016;164(7):456-63. https://doi.org/10.7326/M15-0983

39. Petrik AF, Le T, Keast E, Rivelli J, Bigler K, Green B, et al. Predictors of Colorectal Cancer Screening Prior to Implementation of a Large Pragmatic Trial in Federally Qualified Health Centers. J Community Health. 2018;43(1):128-36. https://doi.org/10.1007/s10900-017-0395-7

40. U. S. Preventive Services Task Force, Bibbins-Domingo K, Grossman DC, Curry SJ, Davidson KW, Epling Jr JW, et al. Screening for
Colorectal Cancer: US Preventive Services Task Force Recommendation Statement. JAMA. 2016;315(23):2564-75. https://doi.org/10.1001/ jama.2016.5989

41. Shapiro JA, Seeff LC, Nadel MR. Colorectal cancer-screening tests and associated health behaviors. Am J Prev Med. 2001;21(2):132-7.

42. Pourat N, Kagawa-Singer $\mathbf{M}$, Breen N, Sripipatana A. Access versus acculturation: identifying modifiable factors to promote cancer screening among Asian American women. Med Care. 2010;48(12):1088-96. https://doi.org/10.1097/MLR.0b013e3181f53542

43. Green BB, Wang CY, Anderson ML, Chubak J, Meenan RT, Vernon SW, et al. An automated intervention with stepped increases in support to increase uptake of colorectal cancer screening: a randomized trial. Ann Intern Med. 2013;158(5 Pt 1):301-11. https://doi.org/10.7326/00034819-158-5-201303050-00002

44. Ford I, Norrie J. Pragmatic Trials. N Engl J Med. 2016;375(5):454-63. https://doi.org/10.1056/NEJMra1510059

45. Yurkovich M, Avina-Zubieta JA. Thomas J, Gorenchtein M, Lacaille D. A systematic review identifies valid comorbidity indices derived from administrative health data. J Clin Epidemiol. 2015;68(1):3-14. https:// doi.org/10.1016/j.jclinepi.2014.09.010 